\title{
The Most Influential Factor to Pass Rate of Modified OSCE Exam on Student Batch 2 during Pandemic Period
}

\author{
Mia Kusmiati' ${ }^{1}$,ika Nilapsari' ${ }^{1}$, Annisa R Furqaani ${ }^{1}$, Miranti Kania Dewi ${ }^{1}$ \\ ${ }^{1}$ Universitas Islam Bandung, Indonesia
}

\begin{abstract}
The Objective structure clinical examination is an assessment tool to evaluate clinical skills. There are many factors that influence to pass rate of modified OSCE. Moreover, during online learning implementation, there are some barriers. The aim of the study is to determine the most influential factor that contributing to achieving the learning outcome in terms of passing rate modified online OSCE. An observational study was chosen involving 87 medical students batch 2 . Sample size calculation used the formulation of an estimated proportion population with a simple random strategy. This study employed a questionnaire of online skill learning that was made by the researcher through analysis of factor exploratory. The participants were asked to score their agreement on the five-Likert scale. Using SPSS version 24 and software of AMOS 26, we analyzed the data for simple linear regression and structural equation modeling (SEM). Results were summarized following 2 factors that influencing pass rate of modified OSCE online, in terms of transactional distance ( $p$ value $=0.001, r=0.235$ ) and learning platform availability ((p value $=0.013, \mathrm{r}=0.087)$. Our finding highlights that self-reflection and student access to resources have significant contributions toward independent learner characteristics. This study has contributed to solving the problem regarding the foundational concept for the requirement of online learning. The theoretical concept of a learning platform also enhances online teaching. Foremost and utmost that self-reflection and student access to resources have become two important factors to autonomy learning. The major strength of this study is the systematic manner in which it was conducted.
\end{abstract}

Keywords: Influence factor, modified OSCE, passing rate, online learning

This is an open access article under the CC-BY-NC license

\section{INTRODUCTION}

The COVID 19 pandemic has led to a shift in teaching methods in undergraduate medical education to online or blended learning. One of the domains in medical education is clinical skills that need to be trained from the start, including methods of assessment of learning outcomes. The learning process of clinical skills is among the most complicated applied online because it requires standard patients and supporting equipment to perform clinical skills learning activities. However, evaluating the effectiveness of online and blended teaching remains difficult. This is due to the pandemic situation that causes the increasing use of technology in medical education. At the same time, the significance of online learning in the skill domain is influenced by many factors. Some factors yield obstacles for online learning, such as administrative issues, social interaction, academic skills, technical skills, learner motivation, time and support for studies, technical problems, cost, and access to the internet (Pei and $\mathrm{Wu}, 2019$ ). The Objective Structured Clinical Examination (OSCE) is a valid, reliable, and reproducible assessment method that

Corresponding author

Mia Kusmiati, dr.mia74@gmail.com

DOI: (to be processed)

Research Synergy Foundation 
verifies clinical competencies objectively in a structured way, and it is widely used in health profession education (Hytönen et al., 2020).

In Indonesia and other countries in the world, however, health profession education pondered it necessary to set a modified online OSCE not only to sustain students' continued academic process but also to secure a sufficient workforce. (Hytönen et al., 2020) The simplest format consisted of a CD-/DVD-based video lecture that was recorded from a live class and then uploaded to the internet web, and the most advanced format was a digital platform that licensed students to accept static learning resources(Pei and $\mathrm{Wu}, 2019)$. This format more facilitated interaction with teachers, classmates, and courseware for responsive feedback, or we call name asynchronous online learning. The pandemic situation affects the OSCE execution in undergraduate medical education. Thereby, it was implemented the modified OSCE exam. Yet, the effectiveness of this assessment ought to be evaluated in terms of achieving the learning outcome. Until now, there has been no evaluation on the implementation that has been running, and no one has seen how the perception of learners towards online skill learning methods. The formats of online learning used on clinical skills were various in some education centers. The study's aim is to identify the most influential factor to achievement of modified online OSCE and to evaluate the student's learning behavior during online activities.

\section{LITERATURE REVIEW}

Based on the article review, there are three components that influence the effectiveness of online or blended learning, in which transactional distance, cognitive, social, and teaching presences, and Independent learners. Moore stated that transactional distance is a social, psychological, and relational distance between teachers and learners that is fluid and manageable based on a function of dialogue and structure. Meanwhile, presence in learning is to be a prerequisite to the engagement of the teachinglearning process. Three kinds of presence need to be presented; "Cognitive presence" indicates the degree to which students can create meaning through constant exchanges of thoughts-questioning, answering, brainstorming, discussing, and problem-solving (Rhim and Han, 2020). "Social presence" implicates personal feelings, emotions, questions, and characteristics into the community that is needed to nourish cognitive presence. Whereas, teaching presence refers to the design of the educational experiences and facilitation of a teacher to encourage and enrich two presences previously. Teaching presence intends to realize the useful learning outcome(Rhim and Han, 2020). A tool was arranged to reach the intention of evaluation on skill learning online based on three foundational concepts as mention before.

The framing of the instrument should have relied on the existing theoretical concept. Online learning is widely used in medical education lead to relevance one perspective under a medical student (Sandhu and de Wolf, 2020). Learning behavior toward clinical skill course of medical education reflects a noticeable behavioral pattern that students show as they undertake to learn tasks (Klug et al., 2013). Positive learning behavior supplies students with a time portion that intentionally forces them regarding learning goals (Giannakos et al., 2020). One of the most assessment methods that widely used to estimate targeted competence of clinical skill was OSCE. During pandemic situation assessment method has led to using modified online OSCE (Objective Structured Clinical Examination) (Hytönen et al., 2020). The assessment criteria of OSCE were settled as a checklist containing pre-determined items. There is no feedback given during the modified OSCE online, yet students were permitted to perceive the assessment criteria immediately after the test (Hytönen et al., 2020). Challenges to online education stated in the medical literature thus far comprise some issues relating to time management, use of technology tools, students' assessment, communication, and the lack of in-person interaction (Rajab, Gazal, and Alkattan, 
2020). Besides, online education may not be equitable in terms of accessibility, availability, and quality of teaching (Rajab, Gazal, and Alkattan, 2020). Based on the above, we need a theoretical basis to develop the new measurement method, especially in assessing the modified online learning.

\section{RESEARCH METHODOLOGY}

Thirty-nine items of the questionnaire were distributed to 87 medical student batch 2. Design of the study comprised one single group-time sequence with an observational method. Item construction was conducted previously based on the foundational concepts of online learning and the characteristic of the individual learner in terms of self-reflection and independent learner. Sample size calculation was determined based on estimation proportion formulation through simple random sampling. The researcher determines the inclusion criteria to participate in this study as follows: the 2nd level medical students who have conducted the modified online OSCE exam in the academic year 2020/2021; assessed by lecturers in the school year in accordance with their respective levels, and know the graduation of each OSCE station through an announcement.

Upon receiving the consent, a total of 87 medical students fulfilled the questionnaire of perception about online learning. The tool consists of 39 items with eight domains or factors as a latent variable. Determining eight domain which was observed relied on analysis of factor exploratory on other students. After a well-constructed item and valid, then distributed to 87 medical students during July 2020 . The participants were asked to score their agreement for each item in the questionnaire on a 5-point Likert scale ranging from 1 (disagree) to 5 (strongly agree).

\section{Data analysis}

Using SPSS version 24, we captured the demographic data of participants and analyzed the simple linear regression to determine which factors that influence to passing rate of the modified online OSCE. Analysis moment of structural (AMOS) version 26 also was used to represent structural equation modeling regarding eight variables latent with thirty-nine indicator variables. The variables of this study were identified based on the definition variable following: teaching presence ( 9 items), experiential learning (7 items), student access to the resource (4 items), student preparedness( 3 items), learning platform availability (4items), transactional distance (3 items), self-reflection (4 items), and independent learner (5 items).

This research has received ethical approval from the medical faculty of Bandung Islamic University research ethics committee no. 100/KEPK-Unisba/VII/2021.

\section{FINDINGS AND DISCUSSION}

Table 1 depicts the socio-demographic information of the students $(n=87)$. A majority of the students are females (57.47\%) than males (42.52\%), with an average age of is 20.16 years old. The Year 2 students are those who had sat for their end of the second-semester summative examination. The number of students who taken regular admission tests (79.31\%) was more than specific interest taken (20.69\%) with the ratio of 4:1. Our study also found that the average rate of OSCE pass is $87.07 \%$ (high achievement)

Table 1. Demographic Characteristic of Students Batch 2 following Modified Online OSCE

\begin{tabular}{lcll}
\hline & Characteristic & Frequency & Percentage \\
\hline Gender & male & 37 & $42.53 \%$ \\
& female & 50 & $57.47 \%$
\end{tabular}




\begin{tabular}{llcc} 
Age group & $<=20$ years old & 16 & $19.33 \%$ \\
& $>20$ years old & 71 & $80.66 \%$ \\
Admission test & Particular/PMDK & 18 & $20.69 \%$ \\
& Regular & 69 & $79.31 \%$ \\
Pass Rate (\%) & $<60$ & 1 & $1.23 \%$ \\
& $60-75$ & 32 & $36.78 \%$ \\
& $76-95$ & 20 & $22.99 \%$ \\
& $>95$ & 34 & $39.08 \%$ \\
\hline
\end{tabular}

Table 2 showed that transactional distance is the most influential factor to pass rate of the OSCE and was followed by learning platform availability ( $p$-value $=0.001$ and 0.013 ). The power of correlation on transactional distance amount $23.5 \%$, the rest of $76.5 \%$ were affected by other factors. The amount of $8.7 \%$ component of learning platform contributed to the success the passing rate of OSCE. This is due to the most foundation concept for passing success rate rather than teacher-learner relationship. It was fascinating that interaction between lecturer and student on learning skills has led to the function of dialogue and structure were running well. The result of this study was in accordance with the theoretical concept about the foundation of online teaching-learning (Rhim and Han, 2020).

Our result regarding structural equation modeling of various factors that influence the character of independent learners is described in figure 1.

Table 2. Impact of Some Factors toward Pass Rate of OSCE

\begin{tabular}{lllll} 
Variable Name & Score average & $\begin{array}{l}\text { Pass Rate of } \\
\text { OSCE }\end{array}$ & p-Value & R \\
\hline Teaching presence & $35.345 / 45$ & $87.07 \%$ & 0.774 & 0.031 \\
Experiential Learning & $23.494 / 35$ & $87.07 \%$ & 0.922 & 0.011 \\
Student access & $14.575 / 15$ & $87.07 \%$ & 0.627 & 0.053 \\
Student preparedness & $17.517 / 20$ & $87.07 \%$ & 0.420 & 0.087 \\
Learning platform & $17.517 / 20$ & $87.07 \%$ & 0.013 & 0.087 \\
Transactional & $12.207 / 15$ & $87.07 \%$ & 0.001 & 0.235 \\
Self-reflection & $15.781 / 20$ & $87.07 \%$ & 0.404 & 0.026 \\
Independent learner & $20.126 / 25$ & $87.07 \%$ & 0.455 & 0.081
\end{tabular}




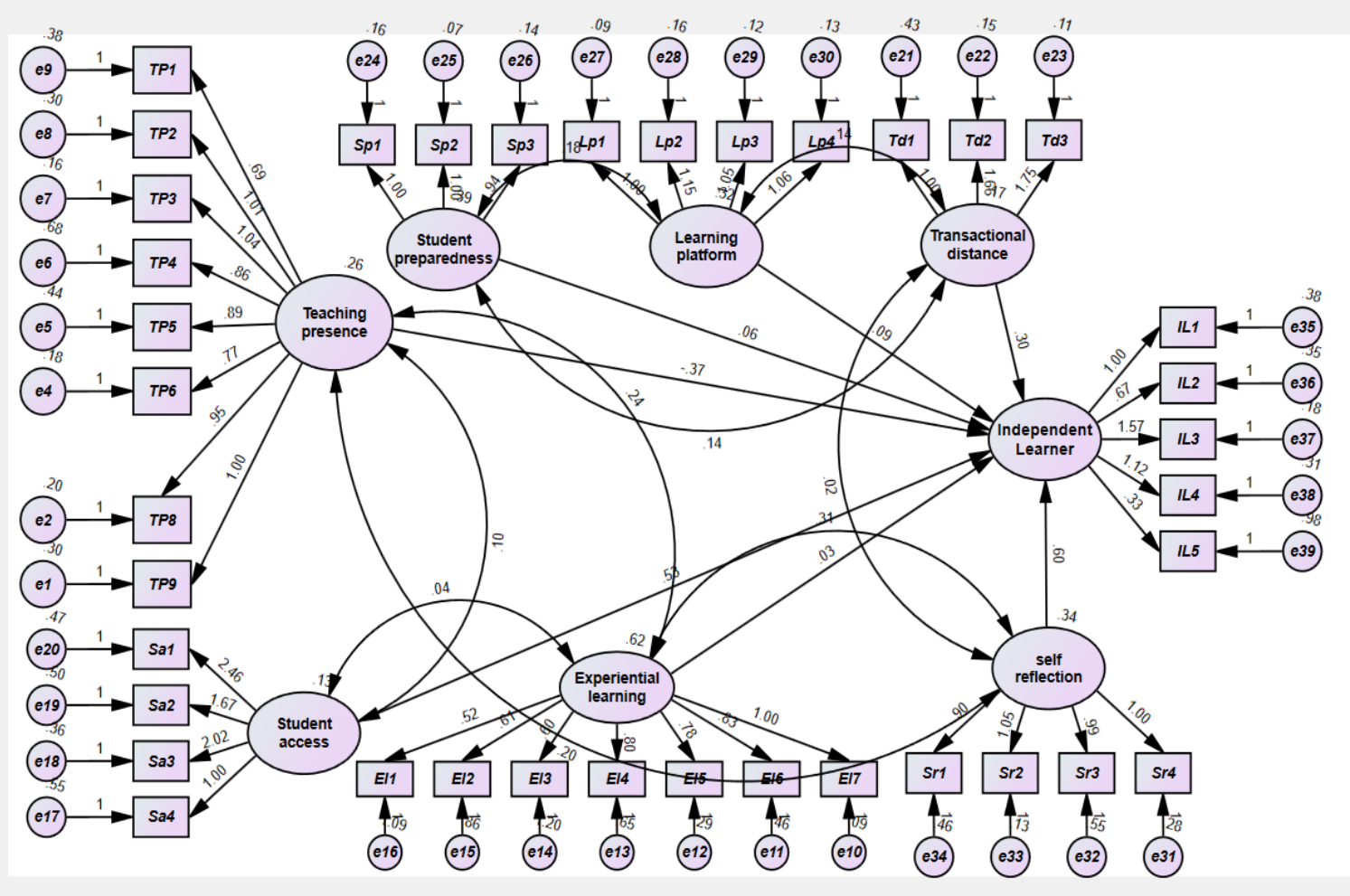

Figure 1. Diagram of structural equation modeling between the characteristic of independent learner with various factors influencing

Based on path analysis, we summary that components of self-reflection and student access to resources were considered as two essential factors that influence independent learners (with the critical rate of 0.60 and 0.53 ). Out of four indicator variables on the self-reflection component, item sr2 (I got feedback and was given the opportunity for reflection after online learning skills) is most represented its latent variable (self-reflection). Figure 1 also showed that the latent variable of student access to resources (Sa) has four indicator variables, with the strongest indicator being item sa1(Learning guide and demonstration video have could be accessed on digital learning platform by online) with the critical rate of 2.46. Meanwhile, the factor of independent learner has five indicator variables (IL1-IL5). The goodness of fit parameters have been achieved in terms of Chi-square/df (CMIN), which has a value of 2.179, RMSEA of $0.00(<0.08)$, and 0.581 of the goodness of fit index (GFI $>0.5$ ) (Widarjono, 2015).

\section{CONCLUSION AND FURTHER RESEARCH}

Our study revealed that there had been a positive impact of the learning platform availability and transactional distance toward the passing rate of the modified online OSCE. Overall, our work also depicts that self-reflection and student's access to resources were the most influential aspect toward student's readiness to learn independently.

However, some limitations are worthy of mention here. First, this study was performed in one faculty of medicine in Bandung. There could be a limitation of generalizing when applied in the other 
research. Second, the relatively small sample size in taking the data has constrained our ability to obtain more information was due to the pandemic COVID-19 situation.

We suggested future work will investigate the other factor shared that influences the pass rate of modified online OSCE on medical faculty and more elaborate each domain of perception as an existing theoretical concept.

\section{REFERENCES}

Giannakos, M. N. et al. (2020) 'Fitbit for learning: Towards capturing the learning experience using wearable sensing', International Journal of Human-Computer Studies, 136(November 2019), pp. 1-14. DOI: 10.1016/j.ijhcs.2019.102384.

Hytönen, H. et al. (2020) 'Modification of national OSCE due to COVID-19 - Implementation and students' feedback', European Journal of Dental Education, (July 2020), pp. 1-10. DOI: 10.1111/eje.12646.

Klug, J. et al. (2013) 'Diagnostic competence of teachers: A process model that accounts for diagnosing learning behavior tested by means of a case scenario', Teaching and Teacher Education, 30(1), pp. 38-46. DOI: 10.1016/j.tate.2012.10.004.

Pei, L. and Wu, H. (2019) 'Does online learning work better than offline learning in undergraduate medical education? A systematic review and meta-analysis', Medical Education Online, 24(1). DOI: 10.1080/10872981.2019.1666538.

Rajab, M. H., Gazal, A. M. and Alkattan, K. (2020) 'Challenges to Online Medical Education During the COVID-19 Pandemic', Cureus, 12(7). DOI: 10.7759/cureus.8966.

Rhim, H. C. and Han, H. (2020) 'Teaching online: Foundational concepts of online learning and practical guidelines', Korean Journal of Medical Education, 32(2), pp. 175-183. DOI: 10.3946/KJME.2020.171.

Sandhu, P. and de Wolf, M. (2020) 'The impact of COVID-19 on the undergraduate medical curriculum', Medical Education Online, 25(1), pp. 4-5. DOI: 10.1080/10872981.2020.1764740.

Widarjono, A. (2015) Applied multivariate analysis with SPSS program, AMOS, and SMARTPLS. 2nd editio. Yogyakarta, Indonesia: UPP STIM YKPN. 